\title{
Patient Safety Applications for Improving Health Care Quality
}

\author{
Rosyidah, Septian Emma Dwi Jatmika
}

Department of Public Health, Universitas Ahmad Dahlan, Yogyakarta, Indonesia

\section{Article Info \\ Article history: \\ Received May 15, 2015 \\ Revised Aug 12, 2015 \\ Accepted Aug 27, 2015}

\section{Keyword:}

Emergency installation

Health care quality

Medical staff

Patient safety

Public Hospital

\begin{abstract}
Patient safety is the fundamental thing that needs to be taken care by medical staff when giving health care to patient, especially in the Emergency Installation. PKU Muhammadiyah Public Hospital Bantul has implemented Patient safety well in providing services for patients. Expected to be a reference for other hospitals to implement Patient safety as well as efforts to improve the quality of health services, but do not close the possibility there were some deficiencies that could be made a suggestion for the PKU Muhammadiyah Bantul Hospital. The aim of this research, to find out more detail how application of Patient safety in Emergency Installation PKU Muhammadiyah Bantul Public Hospital in 2014. This was qualitative observational study, using research subjects: The Head of the medical service, 1 officer of emergency Installation, the head of disaster management, 1 medical doctor, 1 nurse, and 4 patients that were taken with inclusion criteria: getting inpatient in PKU Muhammadiyah Bantul Public Hospital more than one day. Based on the result can be concluded, facilities, equipment, drugs, procedures, and activities of officers at Emergency Installation at PKU Muhammadiyah Bantul Public Hospital, as well as the application process were in accordance with the Guidelines of Observation Guidelines Patient Safety 2008 Survey, and Guidelines for Accreditation of Hospital Emergency Services Specific Guidelines (revised edition 2007), hospital regulations (No.44/2009), and patient safety procedures 2008. Patient perceived output includes five dimensions of quality (Tangible, Reliable, Responsiveness, Assurance and Empathy) patients have the same perception of good and satisfying.
\end{abstract}

Copyright (C) 2015 Institute of Advanced Engineering and Science. All rights reserved.

\section{Corresponding Author:}

Rosyidah,

Department of Public Health,

Universitas Ahmad Dahlan,

Jl. Prof. Dr. Soepomo., S.H. , Janturan, Yogyakarta 55164, Phone (0274) 381523, 379418.

Email: rosyidah@ikm.uad.ac.id

\section{INTRODUCTION}

Patient safety and security is the fundamental thing that needs to be taken care of by medical staff while providing health care services to patients [1]. The goal is to prevent the occurrence of danger or injury to the patient during the treatment process [2].

One of the facts of the patient safety released by the WHO (World Health Organization) that in developing countries one out of ten patients suffered injuries when getting health care. The WHO reported from various countries that adverse event (KTD) inpatients of 3-16\%. Genesis is not expected in New Zealand reported ranged from $12.9 \%$ of inpatient [3], the United Kingdom reported ranged from 10.8\% [4], whereas in Canada ranged from 7.5\% [5]. Results of the study of patient safety in the United States in the late 1990s found the figure of $3.9 \%$ and $2.7 \%$ inpatients of adverse event [6]-[7]. Twenty years later, measurements with the Global Trigger Tool shows that adverse event increased 10-fold (became 32\%) [8]. 
The issue of patient safety in Indonesia started to be discussed in 2000, followed by the first study at 15 hospitals with medical record 4500 . The results show that the figures vary widely, i.e. adverse event $8.0 \%$ 98.2\% for fault diagnosis and 4.1\%-91.6\% for error treatment [9].

Location of high-risk in hospitals (such as installation of emergency rooms, intensive care units and operating rooms) are always a concern in the study of patient safety. Considering how important the mission hospital to be able to provide the best health services to patients requiring hospitals to try to reduce medical errorsas a part of his appreciation of humanity, then the developed system Patient safety designed capable to respond to existing problems.

PKU Muhammadiyah Public Hospital at Bantul has implemented patient safety well in providing services for patients. The hospital is expected to be a reference for other hospitals to implement patient safety as well as efforts to improve the quality of health services. But do not close the possibility there were still some deficiencies that could be made a suggestion for the PKU Muhammadiyah Bantul. Therefore researchers interested to observe more detail how application of patient safety in Emergency Installations PKU Muhammadiyah Bantul Public Hospital [10].

\section{RESEARCH METHOD}

This research was conducted at the Emergency Installation of PKU Muhammadiyah Bantul Public Hospital using qualitative observational study. The informants are the head of medical services, one medical doctor at Emergency Installation, one emergency installation nurse, one the head of disaster management, and four patients taken with inclusion criteria: Was getting inpatient class III at PKU Muhammadiyah Bantul Hospital when doing research, has treated more than one day registered inpatient department. The instruments were in the form of (1) Structured Interview (2) The checklist was adjusted with Patient Safety Observation Guidelines 2008 and Hospital Accreditation Survey Guidelines Specific to Medical Emergency Service (Revised edition 2007) [11].

\section{RESULTS AND ANALYSIS}

\subsection{Analysis of the implementation of Patient Safety on the standard Input at Emergency Installation of PKU Muhammadiyah Bantul Public Hospital}

After the observation is done thoroughly started standard 1 to standard 7, all the standard items in accordance with the Guidelines of observation Guidelines Patient Safety 2008 Survey and guidelines for accreditation of Hospital Emergency Services Scientific Guidelines (revised edition 2007) [11]. Another standard is Hospital regulations No. 44/2009, procedures and Patient Safety 2008. As explained by Donabedean, quality of service is the service that corresponds to standard [12]. If seen as standard:

\subsubsection{Standard 1. Philosophy and Objectives to be achieved}

On this standard, all the items reach a score of 5, meaning that Emergency Installation of PKU Muhammadiyah Bantul Public Hospital can provide emergency services to the community suffering from acute illnesses and injuries, according to the standard. Item S.1.P.1. The hospital hosts emergency services for 24 hours continuously. According to the results of observation and interviews with medical staffat Emergency Installation services are provided 24 hours continuously. S.1.P.2 There is installation or Emergency Installation functionally separate from other service units. At the time of observation in Emergency Installation functionally separate Emergency Installation with other units. The evidence is complete with an organizational structure and task descriptions for medical staffat Emergency Installation. S.1.P.3. Policies and procedures on patients who are not classified as acute and critical medical treatment that comes in Installation of Emergency. This item is also in accordance with the standard Observation Guidelines, Guidelines for Patient Safety 2008 Survey and Guidelines for Accreditation of Hospital Emergency Services Specific Guidelines (revised edition 2007) [11].

\subsubsection{Standard 2. Administration and Management}

Emergency installation must be organized, led and integrated with other parts and installation of other hospitals. S.2.P.1. Installation of Emergency come with organizational charts, job descriptions accompanied the division of authority and mechanisms working relationship with other work units in the hospital. S.2.P.2 There is a schedule of daily to keep your doctor, nurse, and other supporters of the officer on duty at the Emergency Installation. Although there are medical staff who are continuing their study, but the turn of duty and service tasks can be done with a code of conduct. S.2.P.3. There're instructions and the information provided for the community to ensure an ease, smoothness and order in providing services in 
Installation of Emergency [11] Based on observation, can be known to the ease of access and information provided by medical staffat Emergency Installation and Groove on every cover of the Ministry and in the medical record.

\subsubsection{Standard 3. Staff and Leadership}

Installation of Emergency is led by physicians who have received emergency training, assisted by medical doctor, nurse, non medical staff and skilled non-medical staff. On every item in the third standard (a standard 3.1 to 3.5) is in compliance with the Guidelines of Observation Guidelines Patient Safety 2008 Survey and Guidelines for Accreditation of Hospital Emergency Services Specific Guidelines (revised edition 2007), hospital regulations No.44/2009, and Patient Safety Procedures in 2008. As presented in the interview by Emergency Installation's doctor, Emergency Installation's nurse and Emergency Installation's Chief Medic Disaster Committee, periodic training implemented to improve the competence of medical staff at Emergency Installation, including training on disaster emergency response. Because PKU Muhammadiyah Public Hospital liveliness in emergency disaster often get a champion one in 2014 and 2013 got the winner 1 from PERSI for Emergency and disaster management's competition. Patient Safety's Management in Emergency Installation is handled by Patient Safety's Team that evaluated periodically by Internal Quality's Team of PKU Muhammadiyah Bantul Public Hospital. Plan ahead according to information from the Director of PKU Muhammadiyah Bantul Public Hospital, Chief Medic Disaster Committee, the doctor and the doctor in charge of the patient safety at Emergency Installation convey if Patient Safety's Team into the future will be under direct and evaluated by the medical service.

\subsubsection{Standard 4. Facilities and Equipment}

Facilities provided must guarantee the effectiveness of the emergency patient service within 24 hours continuously.

S.4.P.1: There is relief for four-wheeled vehicles from outside to reach the location of installation/Rescue Emergency Unit in hospitals, and the ease of transporting patients to and from the direction of Emergency Installation in Hospital.

Buildings for Ministry of Emergency Patients must cope in such a way that the patient emergency relief can be carried out with optimal. It is stated in the guidelines of the Emergency Ministry in 1995. The location of the Emergency Installation Muhammadiyah Bantul Public Hospital is easily reached by a clear direction from the street as well as from within. The Emergency Installation is facing forward so that the ambulance did not need to resign for accessing the Emergency Installation. As for ease of transporting patients to and from the Emergency Installation from direction in the Hospital, can through the door next to the Emergency Installation.

S.4.P.2: There is a separation of the checkpoints and actions in accordance with the conditions of his illness.

There are six parts at Emergency Installation of Muhammadiyah Bantul Public Hospital which consists of resuscitation triage room, space, space action, examination room, just my assessment and dugout space officer. Unfortunately, there is not yet a special waiting area for families. There are regulations for patient's family that the maximum amount of family members who may keep the patient was only one person. It is intended that the care of patients in the Emergency Installation can run optimally. However, the bathrooms for the patient or the patient's family are separated with a bathroom attendant. Room service OK (Operatie Kamer) in PKU Muhammadiyah Bantul Public Hospital open 24 hours. Therefore, all procedures of surgery for patients is not done in the basement of Emergency Installation but in space the OK. Room's arrangement of the Emergency Installation is arranged such that the flow smooth and easy activities sufferers are controlled by the duty officer.

Triage is the first stage in the Hospital's Emergency Installation where the patient assessment based on therapeutic needs and available resources [13]. Labeling red for a state of emergency, yellow to green for urgent circumstances and circumstances of non-urgent respectively have been applied properly when doing triage and written in the medical record.

S.4.P.3: Procurement and provision of equipment, drugs, materials, fluid infusions are done in accordance with the standard on the manual Emergency Services.

The availability of equipment and drugs in the Emergency Installation of PKU Muhammadiyah Bantul Public Hospital in accordance with standard equipment at Emergency InstallationHospital Type c. There are nine kinds of tools and remedies like drugs for resuscitation, the cure for "life support," tool-a cure for diagnostic, a drug in accordance with hospital type, the tools of drug therapy in accordance with hospital type and medical non-drug, such as audio visual, training aids, and safety such as fire engines. As for the type 
of equipment necessary for the hospital there are nine classes C equipment, namely a defibrillator, EKG, operating lights (mobile operating), sterilizer, suction pump, infusion pump, syringe pump, anesthesia machine, and pulse ox meter. In fact, Emergency Installation of PKU Muhammadiyah Bantul Public Hospital is the disaster preparedness verified credentials.

S.4.P.4: There is a communication system to ensure a smooth relationship between the Emergency Installation with:

a. Unit others inside and outside the runah pain associated

b. Hospital and other health facilities

c. Ambulance Service

d. Firefighters unit

e. Konsulen SMF at Emergency Installation

Means of communication at Emergency Installation of PKU Muhammadiyah Bantul Public Hospital well enough where the Emergency Installation has internal and extern phone so communication and transfer of information between health care professions are coordinated seamlessly and effectively. Thus, the coordination of the Ministry can be done on an ongoing basis so that all stages of the service transition between service unit can run nice and smoothly.

S.4.P.5: There are provisions regarding inspection, maintenance and repair of equipment at regular intervals.

All the equipment is in process done Emergency Installation maintenance and calibration on a regular basis. The process of maintenance was done by an internal team at PKU Muhammadiyah Bantul Public Hospital. As for the calibration of the equipment, the PKU Muhammadiyah Bantul Public Hospital bring special office hospital of the Health Ministry of Indonesia.

\subsubsection{Standard 5. Policies and Procedures}

There should be policies and procedures implementation written in units that are always reviewed and improved (when necessary) and easily seen by all office hospital.

All standard 5 and item S.5.P.1 to S.5.P. 4 get a score of 5 meaning that is in compliance with the Guidelines of Observation Guidelines Patient Safety 2008 Survey and Guidelines for Accreditation of Hospital Emergency Services Specific Guidelines (revised edition 2007), hospital regulations No.44/2009, and Patient Safety Procedures 2008 [11].

\subsubsection{Standard 6. Staff Development and Education Programs}

Emergency Installation can be used for education (in-service training) and continuing education for officers.

All items on the standard 6.(S.6.P.1 to S.6.P.6) get a score of 5 and in accordance with the Guidelines for Patient Safety2008 Survey and Guidelines for Accreditation of Hospital Emergency Services Specific Guidelines (revised edition 2007), hospital regulations No.44/2009, and Patient Safety Procedures 2008 [11]. Development competence of medical staff at Emergency Installation is good because on a regular basis and in accordance with the need of upgrading medical staff skills at Emergency Installation.

\subsubsection{Standard 7. Evaluation and Quality Control}

This is a standard indicator of the presence ofassessment of ability and effort the results serviceIGD/Emergency Installation continuously. All items on the standard 7 (S.7.P.1 to S.7.P.5) Gets a score of 5 meaning in accordance with the expected indicate to Hospital and accordance withGuidelines on Patient Safety 2008 Survey and Guidelines for Accreditation of Hospital Emergency Services Specific Guidelines (revised edition 2007), hospital regulations No.44/2009, and Patient Safety Procedures 2008 [11]. Based on the results of interviews with the Responsible physician in Emergency Installation that evaluation for Emergency Installation and Patient Safety is carried out by a team of the quality of the PKU Muhammadiyah Bantul Public Hospital , routinely. Plan ahead for Patient Safety will be on the evaluation directly by medical services.

\subsection{Analysis of application of Patient Safety In the process of service at Emergency Installation of PKU Muhammadiyah Bantul Public Hospital}

The application of patient safety standards can process at good value, with indicators alignment of operational guidelines, SOPS and conditions of Observation Guidelines for Patient Safety 2008 Survey and Guidelines for Accreditation of Hospital Emergency Services Specific Guidelines (revised edition 2007), hospital regulations (No.44/2009), and Patient Safety Procedures in 2008. 
According to the results of interviews with patients may be aware that the service of medical staff at Emergency Installation is good and satisfactory. Evaluation process was done in an orderly implemented by teams of quality, to ensure a smooth implementation of and compliance with the standards or rules that apply. Though in order case report Patient Safetystill needs support from the leadersteams of Patient Safety, but progress in openness and providing reports on cases already performed by medical staff at Emergency Installation. Results of other studies have reported that the cause of the decline in reporting patient safety incidents (IKP) in the hospital was a fear of blame if the report because the culture of patient safety, i.e. no blamingstill not grow evenly across the entire hospital lack of knowledge of the reporting of patient safety incidents (IKP), reluctance to report because of the commitment of the management unit or related, there is no reward of Hospital if reported and lack of liveliness from Hospital Patients Safety Committee [14].

Socialization is also heavily committed to growing awareness of the culture of Patient Safetyin every activity of the Ministry. Awareness ofthe importance of giving priority to the safety of health services should be built and nurtured so that patient safety has always been a major focus in performing the service. Without awareness, then the officer will only carry out service based on the standards and procedures, without regard to patient safety and compliance standards or procedures [15].

\subsection{Analysis of The Output on The Application of Patient Safety at Emergency Installation of PKU Muhammadiyah Bantul Public Hospital}

The indicators used in the evaluation on output implementation of patient safety in the Emergency Installation is the fit with the theory of the assessing health service Parasuraman in 5 dimensions of quality are:Tangible, Reliable, Responsiveness, Assurance and Empathy [16].

Based on observations made by researchers, responses or perceptions of four patients who never get the in service by medical staff of the Emergency Installation, overall state services provided either. Well that is meant in terms of Tangible for completeness means, infrastructure, tools and facilities including the drug received. Reliable or reliability of Medical staff at Emergency Installation all good and workmanlike in providing service, it does have an impact on the dimensions of Assurance or guarantee the safety of the patient being good because patients feel comfortable and calm while getting service by medical staff at Emergency Installation. On dimension of responsiveness of patients assessing that services by medical staff at Emergency Installation already fast the provides and referral in accordance with the results of the diagnosis doctor at Emergency Installation. For example if the patient should immediately to the laboratory for Rontgen or if the patient is improving style then allowed to go home. On dimension of empathy, the patient assessing that medical staff at Emergency Installation are friendly, respect and clear in providing information. Patients also expressed satisfaction for the services provided bymedical staffat Emergency Installation PKU Muhammadiyah Public Hospital.

After conducting interviews and observations, in five dimensions serve equal the inconclusive implementation of Patient Safety in the process of good standards and satisfy patients. Patient safety practices conducted by the hospital are expected to provide benefits in the imaging effort is a positive development in the hospital that is on the rise and the development of a culture of safety (safety culture), communication with patients is growing, the decrease in incidence is not expected with map adverse event (KTD) always exist and current, clinical risk decreases, the complaints and litigation is reduced, increasing the quality of service and the image of the hospitals as well as public confidence increases [17].

Increasingly, health consumer is no longer to be treated as passive recipients of what is deemed to be good for them. They want to be partners in decision making about their own health, and to be involved in designing, managing, and delivering hospital care, in order to ensure hospital safe, effective and appropriate to community needs [18].

\section{CONCLUSION}

Based on the results of observation, interviews with key informants with the triangular, as well as analysis on the standard of service and Patient safety, the Emergency Installation research results can be summed up as follows:

- Standard Input: All of the items on the application of Patient Safety which include facilities, equipment, drugs, procedures, and activities of officers at Emergency Installation at PKU Muhammadiyah Bantul Hospital, is in compliance with the Guidelines of Observation Guidelines Patient Safety 2008 Survey and Guidelines for Accreditation of Hospital Emergency Services Specific Guidelines (revised edition 2007), hospital regulations No.44/2009, and Patient Safety Procedures in 2008.

- Standard Process: The application of Patient Safety is already good and orderly in accordance with operational guidelines, SOPS and guidelines Manual Observation Patient Safety 2008 Survey and 
Guidelines for Accreditation of Hospital Emergency Services Specific Guidelines (revised edition 2007), hospital regulations No.44/2009, and Patient Safety Procedures in 2008.

- Standard Output: The output includes the patient perceived quality (five dimension; Tangible, Reliable, Responsiveness, Assurance and Empathy) all have the same perception of good and satisfying.

\section{ACKNOWLEDGEMENTS}

Managing Director and Patient safety staffs in Emergency Installation at PKU Muhammadiyah Bantul Public Hospital and Institute for Research and Development Universitas Ahmad Dahlan (LPP-UAD).

\section{REFERENCES}

[1] Departement of Health R.I, "Patient Safety Guidelines", Jakarta, 2008.

[2] Departement of Health RI, "Pharmacist Responsibility of The Patient Safety", Jakarta, Direktorat Bina Farmasi Komunitas dan Klinik, 2008.

[3] Davis, P., et al., "Adverse Events in New Zealand Public Hospitals : Principal Findings from a National Survey", New Zealand, The Ministry of Health, 2001.

[4] Vincent, C., Neale, G., Woloshynowych, M., "Adverse Events in British Hospitalas : Preliminary Retrospective Record Review", British Medical Journal , vol/issue: 322(7285), pp. 517-519, 2001.

[5] Baker, G. R., et al., "The Canadian Adverse Events Study : The Incidence of Adverse Events Among Hospital Patients in Canada", Canadian Medical Association Journal, vol/issue: 170(11), pp. 1678-1686, 2004.

[6] Brennan, T. A., et al., "Incidence of adverse events and negligence in hospitalized patients : Results of the Havard Medical Practice Study I", The New England Journal of Medicine, vol/issue: 324(6), pp. 370- 376, 1991.

[7] Thomas, E. J., et al., "Incidence and types of adverse events and negligent care in Utah and Colorado", Medical Care, vol/issue: 38(3), pp. 261-71, 2000.

[8] Classen, D. C., et al., "Global Trigger Tool" shows that adverse events in hospitals may be ten times greaher than previously measured", Health Affairs, vol/issue: 30(4), pp. 581-589, 2011.

[9] Utarini, A., Koentjoro, T., At Thobari, J., "Accreditation of Health care organization, health professional and higher education institution for health personel, Health Project V, Central Java Province", Yogyakarta, Centre for Health Service Management, Faculty of Medicine, Universitas Gadjah Mada, Yogyakarta, 2000.

[10] PKU Muhammadiyah Public Hospital, "Hospital Profile of PKU Muhammadiyah Bantul Public Hospital", Yogyakarta, 2012.

[11] Departement of Health R.I., "Guidelines for Accreditation of Hospital Emergency Services Specific Guidelines (revised edition 2007)", Jakarta, 2008.

[12] Bustami, "Quality Assurance and Accessibility of Health Care", Jakarta, Erlangga, 2011.

[13] Wulansari, D., "Analisys of Patient Safety Attitudes on the Nurses Inpatient of RSU Padma Lalita Muntilan Magelang Hospital", Yogyakarta, 2011.

[14] Iskandar, H., Maksum, H., Nafsiah., "Couses Decreases Incident of Patient Safety Hospital”, Journal of Medecine Brawijaya, vol/issue: 28(1), pp. 70-75, 2014.

[15] Amstrong, M. A., "Handbook of Human Resources Management: Practice To Action. 10th Ed.", London, Kogan Page, 2006.

[16] Widjono, "Management of Quality Health Care.", Surabaya, Airlangga University Press, 1999.

[17] Cahyono, "Building a Culture of Patient Safety in Medical Practice.", Yogyakarta, Kanisius, 2008.

[18] Berrill, J., Healy, J., Edited by Healy, J., Dugdale, P., "Patient Safety First: Hospital Licensure, Certification and Accreditation", Allen \& Unwin, 2009.

\section{BIOGRAPHIES OF AUTHORS}

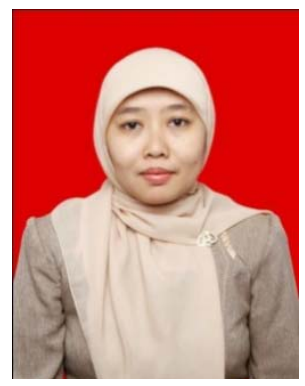

Rosyidah was born on January 30, 1977 in Lampung. The writer is a Lecturer at Hospital Management Department Faculty of Public Health Universitas Ahmad Dahlan. She graduated from Public Health Department Universitas Gadjah Mada in 2004. Independent Consultant of Mapping on the division of role and function in governing the Universal Health Coverage Supported by UNDP. Researcher at Center of Health Financing and Insurance Faculty of Medicine Universitas Gadjah Mada Yogyakarta, and active researcher at Institute for Research and Development Universitas Ahmad Dahlan. 


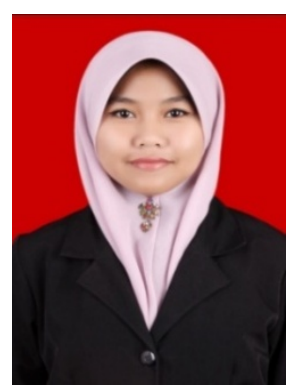

Septian Emma Dwi Jatmika was born on September $26^{\text {th }}$, 1988 in Purbalingga, Central Java, Indonesia. The writer is a lecturer at the Faculty of public health and a researcher at Departement of Research and Development, Universitas Ahmad Dahlan counted since August 2012. The author comlpeted Bachelor Degree at Medical Doctor, Universitas Jendral Soedirman in 2006. Then the authors continue her studies at Masters Degree in Health Promotion, Universitas Diponegoro in 2011. She has specialty in Health Promotion especially tobacco control. She also active member in PPPKMI (Indonesia Health Promotor and Educator Association). 